\title{
Re-emergence of the leaf clip gesture during an alpha takeover affects variation in male chimpanzee loud calls
}

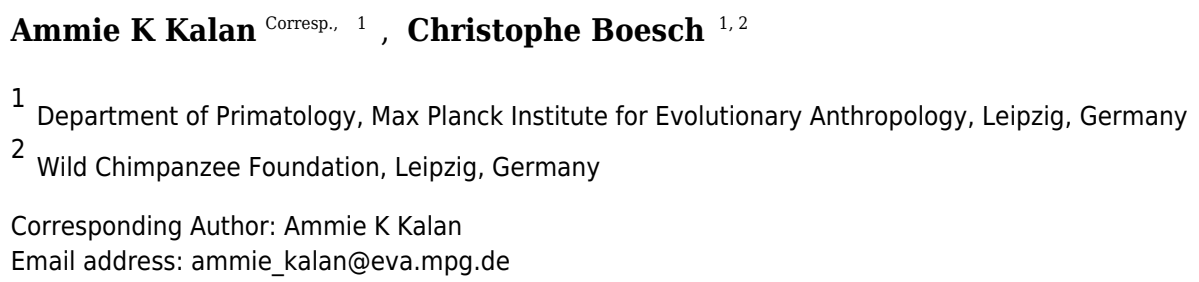

Loud calls are used by many species as long-distance signals for group defense, mate attraction, and inter- and intragroup spacing. Chimpanzee loud calls, or pant hoots, are used in a variety of contexts including group coordination and during male contests. Here, we observed an alpha male takeover in wild chimpanzees (Pan troglodytes verus) during which the leaf clipping gesture re-emerged after disappearing for almost two years in this community. Leaf clipping only occurred in males and was observed almost exclusively prior to pant hoot vocalizations, as has been observed in other chimpanzee communities of the Taï forest in Côte d'Ivoire. Therefore, we hypothesized that leaf clipping may be important for male-male competition by affecting variation in the acoustic properties of male chimpanzee loud calls. We therefore investigated whether pant hoots preceded by leaf clipping differed acoustically from those without, while also testing the influence of social context on pant hoot variation, namely male dominance rank and hierarchy instability, i.e., before, during and after the alpha takeover. We found that pant hoots preceded by leaf clipping were longer, contained more call elements and drum beats, and lower fundamental and peak frequencies. Moreover, during the alpha takeover pant hoots were shorter, contained fewer drum beats and higher fundamental frequencies.

Additionally, pant hoot and aggression rates were also highest during the alpha takeover with leaf clipping more likely to occur on days when pant hooting rates were high. Overall social rank had limited effects on pant hoot variation. We suggest that elevated arousal and aggression during the alpha takeover triggered the re-emergence of leaf clipping and the associated acoustic changes in pant hoots. Further research should focus on the potential mechanisms by which leaf clipping is connected to variation in pant hoots and cross-population comparisons of the behaviour. 


\section{Re-emergence of the leaf clip gesture during an alpha takeover affects}

\section{2 variation in male chimpanzee loud calls}

3 Ammie K. Kalan ${ }^{1 *}$ and Christophe Boesch ${ }^{1,2}$

$4{ }^{1}$ Department of Primatology, Max Planck Institute for Evolutionary Anthropology, Leipzig,

5 Germany

$6{ }^{2}$ Wild Chimpanzee Foundation, Leipzig, Germany

7 *Corresponding author: Ammie K. Kalan; ammie_kalan@eva.mpg.de

8

9

10 
20

21

22

23

24

25

\section{Abstract}

Loud calls are used by many species as long-distance signals for group defense, mate attraction, and inter- and intragroup spacing. Chimpanzee loud calls, or pant hoots, are used in a variety of contexts including group coordination and during male contests. Here, we observed an alpha male takeover in wild chimpanzees (Pan troglodytes verus) during which the leaf clipping gesture re-emerged after disappearing for almost two years in this community. Leaf clipping only occurred in males and was observed almost exclusively prior to pant hoot vocalizations, as has been observed in other chimpanzee communities of the Taï forest in Côte d'Ivoire. Therefore, we hypothesized that leaf clipping may be important for male-male competition by affecting variation in the acoustic properties of male chimpanzee loud calls. We therefore investigated whether pant hoots preceded by leaf clipping differed acoustically from those without, while also testing the influence of social context on pant hoot variation, namely male dominance rank and hierarchy instability, i.e., before, during and after the alpha takeover. We found that pant hoots preceded by leaf clipping were longer, contained more call elements and drum beats, and lower fundamental and peak frequencies. Moreover, during the alpha takeover pant hoots were shorter, contained fewer drum beats and higher fundamental frequencies. Additionally, pant hoot and aggression rates were also highest during the alpha takeover with leaf clipping more likely to occur on days when pant hooting rates were high. Overall social rank had limited effects on pant hoot variation. We suggest that elevated arousal and aggression during the alpha takeover triggered the re-emergence of leaf clipping and the associated acoustic changes in pant hoots. Further research should focus on the potential mechanisms by which leaf clipping is connected to variation in pant hoots and cross-population comparisons of the behaviour. 
44

45

mate competition (Ryan \& Kime, 2003; Delgado, 2006). In mammals, long-distance 'loud calls' are central to male displays that are used to deter potential competitors and attract mates, where listeners can obtain information about the dominance or competitive strength of a male signaler (Fischer et al., 2004; Reby et al., 2005; Pitcher et al., 2014; Benítez et al., 2016). Given the source-filter theory for vocal sound production (Fitch \& Hauser, 2003), larger males are expected to produce lower pitched calls which can serve as reliable cues of their body size and thus competitive ability (Davies \& Halliday, 1978; Fitch, 1997). Support for this relationship has been observed in a variety of birds (Searcy \& Andersson, 1986; Gil \& Gahr, 2002; Nolan \& Hill, 2004), frogs (Davies \& Halliday, 1978; Searcy \& Andersson, 1986; McClelland, Wilczynski \& Ryan, 1996) and mammals (Fitch, 1997; Reby \& McComb, 2003; Sanvito, Galimberti \& Miller, 2007; Vannoni \& McElligott, 2008; Neumann et al., 2010; Puts et al., 2016). Numerous studies have also demonstrated that males in better physical condition usually produce a larger number of calls, call at higher rates or with a longer duration compared to other males (birds (Searcy \& Andersson, 1986; Gil \& Gahr, 2002; Nolan \& Hill, 2004), frogs (Searcy \& Andersson, 1986; Welch, Semlitsch \& Gerhardt, 1998), hyenas (East \& Hofer, 1991) and deer (Reby et al., 2005; Pitcher et al., 2014)). However, studies on non-human primates ('primates' hereafter) have provided mixed results on male traits and vocalization parameters (Mitani, 1985; Clark, 1993;

Kitchen et al., 2003; Wich et al., 2003; Ey, Pfefferle \& Fischer, 2007; Neumann et al., 2010; Barelli et al., 2013; Puts et al., 2016; Benítez et al., 2016). For example, males having a high dominance rank have been associated with low fundamental frequencies in some species (Neumann et al., 2010; Benítez et al., 2016), and higher fundamental frequencies in others (Fischer et al., 2004; Barelli et al., 2013). 

Hobbett, 1975; Clark, 1993; Puts et al., 2016), as well as being individual (Mitani \& Brandt, 1994; Kojima, Izumi \& Ceugniet, 2003; Notman \& Rendall, 2005) and group specific

(Crockford et al., 2004). The pant hoot functions in coordinating group movement (Mitani \& Nishida, 1993; Fedurek, Donnellan \& Slocombe, 2014) and territory defense (Wilson \& Wrangham, 2003), while little is known about its role in regulating within group male-male competition (Muller \& Mitani, 2005). The pant hoot is a compound call traditionally described as consisting of four phases: introduction, build-up, climax and let-down (Marler \& Hobbett, 1975; Crockford et al., 2004; Notman \& Rendall, 2005). Male chimpanzees often incorporate buttress drumming into the climax phase of their pant hoot, where the soles of the hands and feet are hit repeatedly against buttress roots of trees (Arcadi, Robert \& Boesch, 1998). The highest ranking male, the alpha, is often the most vocal (Clark, 1993; Fedurek et al., 2016), as in other mammals (Pitcher et al., 2014), but little is known about the variation in acoustic properties of the pant hoot beyond individual differences (Marler \& Hobbett, 1975; Mitani \& Brandt, 1994; Kojima, Izumi \& Ceugniet, 2003; Notman \& Rendall, 2005). A recent study showed that pant hoot rates of male chimpanzees were positively correlated with urinary testosterone levels and males with higher testosterone produced higher peak frequencies in the climax phase (Fedurek et al., 2016). In addition to buttress drumming, chimpanzees produce other gestural signals in combination with pant hoots. In the Taï forest in Côte d'Ivoire, males occasionally leaf clip immediately preceding their loud call vocalizations (Boesch, 1995). Leaf clipping is a tool-use gesture where a chimpanzee detaches leaves and rips the leaf blade repeatedly between pressed lips or teeth without ingesting it, often producing an audible 'ripping' sound (Nishida, 1980; 
89 Boesch, 1995). It has been documented in multiple chimpanzee populations where it appears to 90 be used in different contexts (Nishida, 1980; Sugiyama, 1981; Boesch, 1995; Watts, 2007) and is

91 therefore considered to be one of many cultural variants present in this species (Whiten et al., 92 1999; Boesch, 2012). The combination of the leaf clip gesture with the pant hoot vocalization is

93

94

95 an example of multisensory communication in chimpanzees, also referred to as a 'free' multimodal signal (Higham \& Hebets, 2013; Wilke et al., 2017), albeit these two signals have limited temporal overlap. Moreover, both signals on their own are also multimodal: comprised of simultaneous audible, facial and gestural components (Liebal, 2013; Video S1). The majority of chimpanzee, and other nonhuman primate vocalizations, are actually 'fixed' multimodal signals, due to the simultaneous coupling of facial expressions with vocalizations that are necessary for producing particular sounds (Higham \& Hebets, 2013; Wilke et al., 2017). Despite the variable definition of the term 'multimodal' in animal communication research (Hobaiter, Byrne \& Zuberbühler, 2017), there is no doubt that a multimodal framework can demonstrate subtle signaling complexities that can otherwise go unnoticed when restricting analyses to a single modality (Liebal, 2013; Wilke et al., 2017). Therefore, we specifically investigated the effect on chimpanzee pant hoots when coupled with leaf clipping because the combination of these signals suggests a degree of flexibility that had hitherto not been examined.

Here, we documented the re-emergence of the leaf clipping gesture during an alpha male takeover in a habituated chimpanzee community (Boesch \& Boesch-Achermann, 2000). Almost two years had passed since the last time leaf clipping had been observed in this group. At Taï, leaf clipping is primarily produced by adult males in contexts of social frustration where it is done immediately preceding a pant hoot vocalization and is rarely produced on its own (Boesch, 1995). To our knowledge, leaf clipping occurs in both sexes in other chimpanzee populations and 
112 appears to be disassociated from the pant hoot vocalization altogether (Boesch, 2012). For

113 example, in Mahale, males and estrus females use leaf clipping to initiate copulations (Nishida,

114 1980), and this is similarly observed in Budongo (Hobaiter \& Byrne, 2014), Gombe and Ngogo

115 (Watts, 2007). Meanwhile, male and female chimpanzees in Bossou, Guinea have been observed

116 to engage in leaf clipping in a variety of contexts including frustration, copulation and play

117 (Sugiyama, 1981). However, due to its relatively low rate of occurrence in wild populations

118 (Boesch, 1995; Watts, 2007) and the lack of information about this nuanced behaviour, it

119 remains a poorly understood socio-cultural trait in wild chimpanzees.

The aim of this study was therefore to assess acoustic variation in the pant hoot with

121

122

123

124

125

126

127 respect to the occurrence of leaf clipping while also investigating the effects of male dominance rank and male-male competition during the alpha takeover period on chimpanzee loud calls. We specifically investigated acoustic cues typically associated with male competitive ability in the vocalizations of primates and other mammals (Clark, 1993; Wich et al., 2003; Reby et al., 2005; Neumann et al., 2010; Pitcher et al., 2014; Benítez et al., 2016), and predicted that leaf clipping and higher ranking males would produce pant hoots with lower fundamental frequencies, a longer duration, and contain more call elements and buttress drumming. Additionally, since disruptions in the dominance hierarchy are expected to increase male-male competition (Muller \& Mitani, 2005; Georgiev, 2012), we predicted that the alpha male takeover provided a critical social context for male signals to be modulated, including pant hoots and leaf clipping at Taï. Therefore, we further tested whether daily rates of male pant hooting and aggression rates were also affected by the period of instability (i.e., before, during and after the alpha takeover) and the occurrence of leaf clipping. 
135 Materials \& Methods

136 All data were collected between July 2011 and May 2012 in the Taï National Park in Côte

137 d'Ivoire. The study subjects were five males from one chimpanzee community, the South group

138 (Boesch, 2012), including 3 adult males (16, 18 and 18 years of age) and 2 sub-adult males both

13913 years of age. All day focal follows were conducted on the five males with the help of a field

140 assistant for a total of 666 hours of observation during which all behavioural activities, social

141 interactions, and vocalizations were continuously noted (Table 1). There were a total of 68 focal

142 follow days for the five males (mean: 9.79 hours; range: 3 - 12.5 hours). The sub-adult males

143 were only followed once it became clear they attained top rank positions ( $3^{\text {rd }}$ and $4^{\text {th }}$ rank) in the

144 hierarchy due to the small group size (19 adults and sub-adult individuals plus 5 infants). All

145 data were collected on wild chimpanzees using non-invasive, observational methods only.

146 In the field, we noted whether a pant hoot was directly preceded by leaf clipping $(<3 \mathrm{~s}$

147 before the start of a pant hoot). Soft, intermittent 'hoos' could sometimes be heard whilst the

148 individual leaf clipped (Video S1), however only if these 'hoos' graded into the start of a pant

149 hoot $(<3 \mathrm{~s})$ were they considered as part of the pant hoot. Leaf clipping observations and

150 recordings of pant hoots (see Acoustic Analyses) were collected during focal follows and ad

151 libitum throughout the study period whenever target males were present (Table 2). Dominance

152 ranks were observed to change twice during the study period: 1) due to the alpha male takeover

153 where the beta and alpha male switched ranks, and 2) due to the disappearance of a high ranked

154 male (Utan) whereby absolute ranks of all individuals changed. Male ranks were assigned by

155 continuous observations of the pant grunt vocalization, specifically the directionality of pant

156 grunts among males since this vocalization is uniquely produced up the hierarchy as an overt

157 signal of submission towards individuals of a higher rank (Boesch \& Boesch-Achermann, 2000; 
158 Muller \& Mitani, 2005). For all pant hoots in this study, we assigned the dominance rank of the

159 male caller based on their rank at the moment the call was emitted.

160

161

162

163

164

165

166

167

168

169

The study duration was divided into three periods: 'before' (3 months), 'during' (1 month) and 'after' (6 months) the alpha male takeover to describe the relative instability in the male hierarchy based on critical observations of physical aggression (first fight observed between the alpha and beta male on October 16, 2011) and the alpha male finally conceding to the beta male by clearly pant grunting to him on November 19, 2011. Therefore, the duration of each period had to be deduced post hoc for these analyses according to the behaviour of the males. Permissions for field research were granted by the Ministère de la Recherche Scientifique, the Ministère de l'Environnement et des Eaux et Forêts and the Office Ivorien des Parcs et Reserves of Côte d'Ivoire (Ref: 11/MINEF/OIPR/DT/CAT).

Acoustic Analyses

Recordings of pant hoot vocalizations were made by AK using a Marantz PMD661 solid state recorder and a Sennheiser ME66/K6 directional microphone handheld with a windshield using a $44 \mathrm{kHz}$ sampling frequency at $24 \mathrm{bits} / \mathrm{s}$. Only recordings where the caller's identity was certain were used and the pant hoot had to be free of any other individual's vocalizations. All pant hoots were recorded at a distance of 3 to $10 \mathrm{~m}$ from the vocalizing chimpanzee. Pant hoots were recorded whenever possible throughout the study period (Table 2) and our final dataset consisted of pant hoots emitted while male chimpanzees were resting $(n=46)$, traveling $(n=124)$, feeding, or arriving to a feeding tree $(n=42)$. For our analyses we did not distinguish between each of these behavioural activities due to the small sample size per individual per category which caused model instability (but see Statistical Analyses and Table S1). In the field it was noted whether any portion of the call was missing from the recording (incomplete) or whether 
181 the pant hoot was recorded in its entirety (complete). Incomplete recordings occurred for 88 of

182 the 212 pant hoots used in these analyses for multiple reasons: noisy recording due to

183 microphone or cable damage, caller moving quickly while vocalizing, background noise or other

184 chimpanzees calling, but in all cases at least one of the three phases was recorded in its entirety.

185 Chimpanzees at Taï rarely include a let-down phase (Arcadi, Robert \& Boesch, 1998); therefore,

186 it was not included in our analyses because it was not observed.

All pant hoot measurements were conducted using the speech analysis freeware Praat

version 5.3 (Boersma, 2001). We calculated acoustic parameters that have already been shown to vary with male quality or dominance in other mammals, including chimpanzees, namely phase and call durations, peak and fundamental frequencies of specific calls, and number of call units per phase of the pant hoot (Marler \& Hobbett, 1975; Clark, 1993; Mitani, Hunley \& Murdoch, 1999; Fedurek et al., 2016). Acoustic measurements were done via visual inspection of a spectrogram whilst simultaneously listening to the pant hoot. Spectrogram settings were always set to a 50 to $8000 \mathrm{kHz}$ viewing range using a window length of $0.01 \mathrm{~s}$. The pant hoots were visually separated into the introduction, build-up and climax phase that are well described and easily discernible (Marler \& Hobbett, 1975; Mitani \& Brandt, 1994; Crockford et al., 2004;

Notman \& Rendall, 2005; Figure 1). The three remaining phases could include a variable number of inhaled and exhaled call elements with the exception of the climax phase which sometimes had no vocal elements but only buttress drumming. Only the number of voiced call elements and/or drum beats in each phase was counted. Pant hoots without climax screams are often produced by chimpanzees, particularly females (Marler \& Hobbett, 1975) and males in this study

202 produced pant hoots which ended without a climax scream and only buttress drumming (57/212 pant hoots in this study). Additionally, males at Taï buttress drum more than other populations 
204 and generally do so in conjunction with pant hoots (Arcadi, Robert \& Boesch, 1998); therefore,

205 we felt it was important to consider drumming as an integral part of the pant hoot for this

206 population (126/212 pant hoots included drumming).

Durations were measured for the total pant hoot and for each of the three phases as well as the drumming bout, excluding leaf clipping, if it occurred (from the onset of the first voiced call or drum beat to the end of the last call or drum beat). The drumming bout was usually solely confined to the climax phase but sometimes overlapped with the end of the build-up. We also measured duration and frequency parameters from a single call isolated from each of the three phases following methods similar to previous studies of chimpanzee pant hoots (Mitani, Hunley \& Murdoch, 1999; Crockford et al., 2004). For example, we selected the middle call of the buildup for analyses since the build-up largely consists of unmodulated calls. If the build-up had an even number of total voiced call elements, we considered the next element as the middle call of the build-up (i.e., for a build-up phase with eight calls we analyzed number five). For the introduction phase we selected the last call for analyses since sometimes the first calls of the pant hoot were missing or of poor recording quality (i.e., incomplete). For the climax, the call with the greatest peak frequency was selected, again as in other studies (Mitani, Hunley \& Murdoch, 1999; Figure 1 for overview of pant hoot variables). calls using the spectral slice tool which automatically calculates a power spectrum of a selected call. The first peak in the spectral slice corresponded to the F0 and the peak with the highest

224 relative amplitude the $\mathrm{pF}$. Values for fundamental and peak frequencies were also verified 225 visually. In total we had 18 quantitative variables assessed for 212 pant hoots produced by 5 chimpanzee males. 


\section{Statistical Analyses}

228 All statistical analyses were conducted in R version 3.2.4 (R Core Team, 2017). We fitted linear

229 mixed models (LMM) and Generalized Linear Mixed Models (Baayen, 2008; Bates et al., 2015)

230 to test the effects of male rank, period of male instability, and leaf clipping on the 18 acoustic

231 variables measured from a total of 212 pant hoots produced by five chimpanzee males of a single

232 community, the South group. Not all pant hoots contained all applicable variables measured

233 therefore sample size varied among models (Table 3). Importantly, we opted to test each acoustic

234 variable separately rather than conduct factor analyses because with a long, compound call such

235 as a pant hoot, one phase of the vocalization does not necessarily constrain other phases, and

236 because we wanted to be able to compare our results with previous chimpanzee studies which

237 investigated particular parts of the pant hoot. Since the number of males in the group differed

238 throughout the study period, before fitting models the value for male rank was standardized to

239 range from 0 to 1 . All models were fitted using the functions 'lmer','glmer' or 'glmer.nb' of the

240 package lme4 in $\mathrm{R}$ (Bates et al., 2016). The response variables were the acoustic variables, and

241 the fixed effects always included the three test predictors (period (before, during, after), leaf

242 clipping $(\mathrm{Y} / \mathrm{N})$, and rank) and one control predictor of whether the recording included the

243 complete pant hoot produced by the chimpanzee or not $(\mathrm{Y} / \mathrm{N})$. All models also included the

244 random effect for caller ID and the random slopes of all fixed effects within caller ID as centered

245 dummy variables (Schielzeth \& Forstmeier, 2009; Barr et al., 2013). We included behavioural

246 activity, (traveling, feeding and resting) for each pant hoot as an additional control variable but

247 the low sample size per individual in the three contexts led to model instability. Therefore, once

248 we ensured that model results did not change with behavioural activity included as a control 
249 (Table S1) we were able to confidently exclude it from final models to get reliable estimates and 250 variances for the test predictors of interest.

251 All continuous response variables (durations, $\mathrm{F} 0$ and $\mathrm{pF}$ variables) were analysed using

252 LMMs (i.e., with a Gaussian error structure and identity link function) with the argument REML

253 set to false in order to assess model significance using likelihood ratio tests. The single poisson

254 model for the number of calls in the introduction was fitted using the function 'glmer' of the

255 package lme4 with the argument family set to poisson and using a log link function (Bates et al.,

256 2016). We fitted negative binomial models for three response variables using the function

257 'glmer.nb' with a log link function (Bates et al., 2016): number of voiced elements in the build-

258 up, the number of elements in the climax and number of drum beats. None of the poisson and

259 negative binomial models suffered from overdispersion (all disperison parameters $<1.13$;

260 (Dobson \& Barnett, 2008)). Gaussian models were checked for normally distributed and

261 homogeneity of residuals by visual inspections of QQ-plots and residuals plotted against fitted

262 values which did not indicate any violation of these assumptions. Additionally, all models were

263 assessed for stability by verifying that model estimates did not vary greatly when individuals

264 were removed one at a time. We further checked for collinearity among predictors by

265 determining Variance Inflation Factors (VIF; Bowerman \& O’Connell, 2000) using the function

266 'vif' of the package car on a linear model with no random effects included (Fox \& Weisberg,

267 2011). All VIFs were between 1.01-1.06 and therefore were no cause for concern. Model

268 significance was assessed using a likelihood ratio test comparing the full versus null model using

269 the function 'anova' with a Chisq approximation (Forstmeier \& Schielzeth, 2011). The null

270 model lacked the fixed effects of period, rank and leaf clipping but was otherwise identical to the

271 full model. If this was significant $(\mathrm{P}<0.05)$ we went on to assess the significance of the 
272 individual test predictors using a likelihood ratio test with the help of the 'drop1' function in $\mathrm{R}$

273 set to using a Chisq approximation (Dobson \& Barnett, 2008; Barr et al., 2013).

275 from the same set of calls, the tests were not independent and therefore required a correction for multiple testing. We used the procedure proposed by Potter and Griffiths (Potter \& Griffiths,

277 2006) which is a modification of Fisher's Omnibus test (Haccou \& Meelis, 1994) accounting for non-independence of the tests by deploying a permutation procedure (Adams \& Anthony, 1996; Manly, 1997). In brief, this approach consists of repeatedly randomizing ('permuting') all response variables simultaneously (i.e., the correlations among the call parameters are retained) and then fitting the respective model for each of the permuted data sets. To further account for the non-independence of calls recorded from the same individuals we restricted the randomizations to take place only within individuals. We conducted 1,000 permutations into which we included the original data as one permutation. For each of the permuted data sets we fitted the same models as for the original data and conducted a full null model comparison for each of the 18 acoustic parameters as described above. We then combined the derived P-values into a single test statistic using ts $=-2 \times \Sigma \log _{\mathrm{e}}(\mathrm{p})$ to obtain the Chi-squared distribution, as expected under the null hypothesis and accounting for the independence of the P-values, from the 1,000 full null model comparison P-values. Finally, we determined the overall P-value as the proportion of permutations revealing a test statistic at least as large as that obtained from the

291 original data set. This revealed an overall P value (accounting for multiple correlated tests) of 2920.002 meaning that our test predictors significantly explained variation in the acoustic 293 parameters. 
We fitted two additional GLMMs to assess the effect of period, rank and leaf clipping on

295

296

297

298

299

300

301

302

303

304

305

306

307

308

309

310

311

312

313

314

315

316

rates of male pant hoot production and aggression based solely on focal follow data of the males

(Table 1). Both GLMMs had a negative binomial error structure with a log link function and

were fitted using the function 'glmer.nb' of the package lme4 (Bates et al., 2016) with the total

number of pant hoots or total number of aggressive interactions as the response variables, respectively. Pant hoots included calls with or without buttress drumming components, and aggressive interactions included all male displays (directed or undirected at conspecifics), chasing and hitting (Muller \& Mitani, 2005), irrespective of whether the focal male was the aggressor or the victim in these interactions. The fixed effects included the three predictors: period, rank and leaf clipping as in the previous models. We also included an offset term for the number of hours (log transformed; McCullagh \& Nelder, 1989) the individual was followed during a given day to control for observation effort (Dobson \& Barnett, 2008). For the aggression rates model, rank was kept as a control fixed effect since we were not particularly interested in rank related effects on aggression and expected higher ranking individuals to be more aggressive, given the way in which chimpanzee dominance is exerted and maintained (Boesch \& Boesch-Achermann, 2000; Muller \& Mitani, 2005). A random effect for focal ID was included, along with all random slopes for the fixed effects within focal ID (Barr et al., 2013). Again, VIFs and dispersion parameters were calculated as explained above and indicated no issues (maximum dispersion parameter: 1.11; maximum VIF 1.37). Additionally, model stability was evaluated as described above, and significance of both models was assessed using a likelihood ratio test in comparison with a respective null model which consisted of only the offset, control predictor (if applicable) as well as random effects and random slopes (Forstmeier \& Schielzeth, 2011). 


\section{Results}

319 At the time of the study, the chimpanzees of this community had not been seen to leaf clip since

320 December 2009 when the group had lost half of its members during a respiratory disease

321 outbreak (unpublished data). None of the remaining adult males were observed to leaf clip

322 following this outbreak despite frequent observations of leaf clipping in the neighbouring

323 habituated community (pers. obs.). We then observed the first alpha male takeover in this group

324 following the outbreak. A physical fight was observed on the evening of October 16, 2011

325 between the alpha and beta male. The beta male at the time, Kuba, was the first individual

326 observed to leaf clip on October 17, 2011 and all other males of the community were present at

327 the time. On October 23, 2011 the contested alpha male, Woodstock, also began to leaf clip and

328 only the beta and alpha male were seen to leaf clip until January 18,2012 when the $5^{\text {th }}$ ranked

329 male at the time, Romario, began to leaf clip. Around this same time, the $3^{\text {rd }}$ ranked male, Utan,

330 disappeared whose body was never recovered. After their first occurrences of leaf clipping all

331 three males continued to occasionally leaf clip but no other male in the group was seen to start

332 leaf clipping during the study period. The leaf clip gesture primarily occurred preceding a pant

333 hoot vocalization, and was thus produced sequentially, not simultaneously (Video S1). We

334 observed a total of 36 leaf clips by the three males during the 11 month study period, 33 of which

335 directly preceded a pant hoot vocalization and of these, 27 pant hoots were recorded and

336 therefore were part of these analyses (Table 2). The remaining 3 leaf clip observations occurred

337 after a pant hoot had ended or accompanied a directed charge at a conspecific without a pant

338 hoot. Of all 36 leaf clipping observations, 10 were accompanied by a direct charge at a

339 conspecific, in 11 cases a female chimpanzee in estrus was present, and in 5 cases the caller was 
340 alone with no other conspecific in sight whilst leaf clipping. Therefore, an audience was visually

341 present for $86 \%(31 / 36)$ of the leaf clipping observations.

Of the 18 acoustic parameters tested in GLMMs for the influence of leaf clipping, period of instability, and rank, 12 had significant full versus null model comparisons (all $\mathrm{P}<0.05$; Table 3). Of these 12 acoustic variables, five measured durations (s) of the whole loud call or parts of the pant hoot, three were the number of call and/or drum elements in the introduction, build-up, and climax phase, and one was the total number of drum beats. The other three significant acoustic parameters were related to frequency parameters; namely, the fundamental frequency (F0) and peak frequency $(\mathrm{pF})$ of the middle call of the build-up and the maximum $\mathrm{pF}$ recorded in the climax (Table 3). For 8 of the 12 models, the control variable complete or incomplete pant hoot recording had a significant impact in these models, controlling for the fact that incomplete recordings were more likely to be shorter or have fewer elements as expected. Therefore, all of our results controlled for the bias possible with an incomplete recording. chimpanzee: the introduction phase was shorter (est $\pm \mathrm{SE}:-0.39 \pm 0.10, \chi^{2}=6.90, \mathrm{df}=1, \mathrm{~N}=173$, $\mathrm{P}=0.0086$; Fig. S1) and contained fewer call elements for higher ranking males $(-0.58 \pm 0.11$, $\chi^{2}=9.31, \mathrm{df}=1, \mathrm{~N}=173, \mathrm{P}=0.0023$; Fig. S1) while the number of voiced calls in the build-up phase was larger for higher ranking males $\left(0.55 \pm 0.21, \chi^{2}=8.07, \mathrm{df}=1, \mathrm{~N}=189, \mathrm{P}=0.0045\right.$; Table 4). 
363 were longer although the duration of the middle call of the build-up was shorter $(-0.34 \pm 0.09$,

$\left.364 \chi^{2}=7.74, \mathrm{df}=1, \mathrm{~N}=189, \mathrm{P}=0.0054\right)$. Additionally, when leaf clipping occurred there were more

365 call elements in the build-up $\left(0.21 \pm 0.12, \chi^{2}=4.33, \mathrm{df}=1, \mathrm{~N}=189, \mathrm{P}=0.037\right)$ and $\operatorname{climax}(0.81 \pm$

$\left.3660.15, \chi^{2}=7.89, \mathrm{df}=1, \mathrm{~N}=189, \mathrm{P}=0.0051\right)$. With respect to buttress drumming, the total duration of

367 drumming was longer when leaf clipping occurred $\left(0.60 \pm 0.12, \chi^{2}=8.84, \mathrm{df}=1, \mathrm{~N}=210\right.$,

$368 \mathrm{P}=0.0029)$ and there were also more drum beats produced by the caller $\left(1.17 \pm 0.28, \chi^{2}=7.62\right.$,

$369 \mathrm{df}=1, \mathrm{~N}=210, \mathrm{P}=0.0058$; Figure 2; Table 3; Table 4; Table S2).

370 Many of the effects observed for leaf clipping on the acoustic properties of pant hoots

371 differed with respect to the effects of instability period on those same acoustic parameters

372 (Figure 2; Table 3; Table 4). In particular, the duration of the total pant hoot was shorter during

373 and after the alpha takeover $\left(\chi^{2}=6.28, \mathrm{df}=2, \mathrm{P}=0.043\right.$; during: est. $\pm \mathrm{SE}:-0.27 \pm 0.12$; after: -0.21

$374 \pm 0.09$ ); the number of voiced calls in the build-up was also lower during the period of instability

$375\left(\chi^{2}=6.42, \mathrm{df}=2, \mathrm{P}=0.040\right.$; during: $-0.31 \pm 0.12$; after: $-0.09 \pm 0.12$; Figure 2$)$ while the duration of

376 the middle call of the build-up phase tended to be longer $\left(\chi^{2}=5.19, \mathrm{df}=2, \mathrm{P}=0.075\right.$; during: $0.46 \pm$

3770.17 ; after: $0.09 \pm 0.08$ ). The F0 of the middle call of the build-up was higher during the alpha

378 takeover $\left(\chi^{2}=12.24, \mathrm{df}=2, \mathrm{P}=0.0022\right.$; during: $2.21 \pm 0.67$; after: $\left.1.61 \pm 0.48\right)$ and likewise with

379 the $\mathrm{pF}$ of the middle call of the build-up $\left(\chi^{2}=10.37, \mathrm{df}=2, \mathrm{P}=0.0056\right.$; during: $0.26 \pm 0.10$; after:

$380 \quad 0.20 \pm 0.06$; Figure 2; Table 3; Table 4; Table S2).

With respect to the climax phase of the pant hoot, the duration of the climax was shorter

during and after the alpha takeover relative to before it occurred $\left(\chi^{2}=16.72, \mathrm{df}=2, \mathrm{P}=0.00023\right.$;

during: $-0.44 \pm 0.10$; after: $-0.31 \pm 0.09)$, and drumming duration was also shorter $\left(\chi^{2}=24.29\right.$,

$\mathrm{df}=2, \mathrm{P}=0.000053$; during: $-0.75 \pm 0.13$; after: $-0.46 \pm 0.12$ ). There were also fewer call elements 
$386 \pm 0.17$; after: $-0.57 \pm 0.15)$ and fewer drum beats $\left(\chi^{2}=17.38, \mathrm{df}=2, \mathrm{P}=0.00017\right.$, during: $-1.54 \pm$

3870.31 ; after: $-0.66 \pm 0.28$ ). One additional variable of the climax was also influenced by the period 388 of instability which was the $\mathrm{pF}$ of the call with the highest energy in the climax phase $\left(\chi^{2}=11.05\right.$, $389 \mathrm{df}=2, \mathrm{P}=0.0040$; during: $-0.34 \pm 0.13$; after: $-0.53 \pm 0.13$ ) where the $\mathrm{pF}$ was lower relative to 390 before the dominance hierarchy was disrupted (Figure 2; Table 3; Table 4; Table S2). affected by the predictors (full versus null model: $\chi^{2}=14.24, \mathrm{df}=4, \mathrm{P}<0.01, \mathrm{~N}=68$ ). In particular, individual pant hoot rates were highest during the alpha takeover $\left(\chi^{2}=6.29, \mathrm{df}=2, \mathrm{P}=0.043\right.$; Figure 3), and also on days when the focal male was seen to leaf clip (est. $\pm \mathrm{SE}=0.46 \pm 0.19, \chi^{2}=5.18$, $\mathrm{df}=1, \mathrm{P}=0.023)$. Rank did not significantly influence pant hoot rates $\left(\chi^{2}=1.61, \mathrm{df}=1, \mathrm{P}=0.20\right)$. Individual aggression rates were also affected by the predictors (full vs. null model: $\chi^{2}=10.14$, $\mathrm{df}=3, \mathrm{P}=0.017, \mathrm{~N}=68$ ) where they were elevated during and after the alpha male takeover relative to before $\left(\chi^{2}=9.98, \mathrm{df}=2, \mathrm{P}<0.01 ;\right.$ Figure 3$)$ but leaf clipping had no significant effect on aggression rates (est. $\left.\pm \mathrm{SE}=-0.07 \pm 0.31, \chi^{2}=0.053, \mathrm{df}=1, \mathrm{P}=0.82\right)$.

Discussion

We found strong support for pant hoots associated with leaf clipping being modified in 403 both spectral and temporal acoustic properties. Pant hoots preceded by leaf clipping had longer phases and call durations, contained a greater number of call elements and drum beats, and had 405 lower fundamental and peak frequencies in the build-up phase. We also found that increased dominance hierarchy instability, resulting from greater male-male competition, affected the acoustic properties of male pant hoots. Pant hoots produced by males during and after an alpha 
408 male takeover had shorter durations, fewer calls and drum beats, and higher fundamental and 409 peak frequencies in the build-up phase relative to before. Additionally, we found daily male pant

410 hoot rates to be higher when the male hierarchy was unstable and on days when males leaf

411 clipped. Therefore, in line with our predictions, the re-emergence of leaf clipping in this

412 chimpanzee community and increased male-male competition were associated with measurable

413 acoustic variation in male loud calls. Male rank did not influence pant hoot rates and we were

414 generally surprised to find only three acoustic parameters varied according to male rank (Table

415 4), albeit we only had five males in this community. However, for the majority of our study

416 period the male dominance hierarchy remained precarious due to the $3^{\text {rd }}$ ranked male

417 disappearing soon after the alpha male takeover; consequently, rank may have had a relatively

418 inconsequential effect in our dataset.

With regards to the motivation for leaf clipping, it is likely not a coincidence that the behaviour re-appeared in this community during a time of intense male-male competition. Although leaf clipping was not directly correlated with daily rates of male aggression the association may be one of a more general context of social frustration as has been described for leaf clipping in other chimpanzee communities (Sugiyama, 1981; Boesch, 1995). Leaf clipping itself is a conspicuous tool-use gesture to receivers in close proximity (Watts, 2007) which may signal a threat of aggression to nearby conspecifics (Boesch, 1995). Indeed, when males begin to leaf clip, nearby conspecifics were often observed to move away from the signaler as if giving

427 him space (pers. obs.). Although not all males in this study were observed to leaf clip (Table 2) clipping, clear indications of high arousal (Muller \& Mitani, 2005; Clutton-Brock, 2016). In 
431 calls with higher peak frequencies although this is often true in both positive and negative

432 affective contexts (Briefer, 2012). Additionally, according to Morton's motivation structural

433 rules (Morton, 1977), animals highly aroused and signaling aggressive intent are expected to

434 produce calls with a lower fundamental frequency which is what we observed in this study when

435 males emitted pant hoots preceded by leaf clipping. Therefore, overall our results support an

436 arousal explanation for the re-emergence of leaf clipping and associated changes to the male

437 chimpanzee loud call.

The contrasting direction of the effects of leaf clipping and hierarchy instability on pant

hoot parameters (Table 4; Table S2) additionally suggests that leaf clipping might help to

alleviate vocal exhaustion caused by an increased pant hoot rate and increased aggression during the alpha takeover period in this study. Vocal exhaustion is characterized by calls becoming

442 shorter with fewer call elements (Fischer et al., 2004) similar to the pant hoots produced by

443 males during the period of instability in this study (Figure 2; Table 4; Table S2). It has also been

444 reported that chimpanzees are energetically stressed during periods of elevated male-male

445 competition which could further contribute to poorly produced pant hoots at this time (Georgiev,

446 2012). However, it is difficult to assess what, if any, physiological benefits leaf clipping could

447 have on pant hoots with respect to sound production or respiration therefore detailed knowledge

448 about chimpanzee vocal production and anatomy is needed to elucidate any potential mechanism

449 at work here. Alternatively, leaf clipping may have emerged as a displacement activity by male

450 chimpanzees to potentially alleviate social stress experienced during this period of hierarchy

451 instability (Maestripieri et al., 1992). However, stress displacement behaviours in animals are

452 usually more self-directed, such as scratching or self-grooming (Maestripieri et al., 1992), and

453 this would not explain why leaf clipping was specifically coupled with pant hoots. 
Although the exact mechanism remains to be investigated, at the very least the leaf

455 clipping behaviour does lengthen the male loud call display by combining the gesture and pant

456 hoot into a more complex multimodal signal. In previous research, leaf clipping has been

457 described as an attention grabbing gesture (Watts, 2007); therefore this behaviour could serve to

458 draw the attention of nearby conspecifics to the signaler and the subsequent pant hoot

459 vocalization. Indeed, audible gestures often form key components of the multimodal signals

460 present in the communicative repertoire of chimpanzees, both in the wild (Wilke et al., 2017;

461 Hobaiter, Byrne \& Zuberbühler, 2017) and in captivity (Leavens, Russell \& Hopkins, 2010).

462 Hence, male chimpanzees may increase the perceived effect of their pant hoots by first capturing

463 the attention of nearby conspecifics using leaf clipping. Regardless, it remains that leaf clipping

464 in combination with pant hoots appears to be a relatively rare behaviour, since the majority of

465 male pant hoots in this community were produced without leaf clipping. Detailed field research

466 into this behaviour, and other nuanced behaviours like leaf clipping, is needed to help

467 disentangle some of the mechanisms proposed above.

\section{Conclusion}

Based on our findings, we show that many acoustic parameters of the male chimpanzee

470 pant hoot were significantly impacted by social instability during an alpha takeover and the occurrence of leaf clipping. Specifically, pant hoots accompanied by leaf clipping were longer,

472 had more call units and drum beats, and lower F0 and pF in the build-up phase. Yet during the 473 period of instability, pant hoots were generally shorter, had fewer call units and drum beats and

474 higher F0 and pF in the build-up phase. Since all males of this chimpanzee community have now 475 been observed to leaf clip, including those that were too young at the time of this study (Taï

476 Chimpanzee Project, unpublished data), the leaf clipping behaviour appears to continue to 
477 maintain itself as a socio-cultural trait in this community. Although in this study we did not

478 examine specific aspects of social learning that presumably enabled the successful transmission

479 of the leaf clipping behaviour in this group, previous chimpanzee research has shown that social

480 learning is at least in part responsible for the spread and maintenance of socio-cultural

481 behaviours (Leeuwen et al., 2012). Further research is needed to assess whether the results

482 reported here are indicative of a general phenomenon whenever leaf clipping and pant hooting

483 co-occur, or if it is limited to this chimpanzee group, and which proximate mechanisms are

484 responsible for the observed acoustic variation.

\section{Acknowledgements}

486 We thank the Ministère de la Recherche Scientifique, the Ministère de l'Environnement et des

487 Eaux et Forêts and the Office Ivorien des Parcs et Reserves for permissions to conduct research

488 in Côte d'Ivoire. For logistical support we thank the Centre Suisse de Recherche Scientifique, the

489 Wild Chimpanzee Foundation, and the Taï Chimpanzee Project, particularly Roman Wittig and

490 all TCP assistants. Special thanks to Roger Mundry for assistance with statistical analyses, Liran

491 Samuni for providing us with her chimpanzee video, Cathy Crockford for helpful discussions on

492 the topic and three peer reviewers for feedback that significantly improved this manuscript.

493

494

495

496

497

498

499

\section{References}

Adams DC., Anthony CD. 1996. Using randomization techniques to analyse behavioural data. Animal Behaviour 51:733-738. DOI: 10.1006/anbe.1996.0077.

Arcadi AC., Robert D., Boesch C. 1998. Buttress drumming by wild chimpanzees: Temporal patterning, phrase integration into loud calls, and preliminary evidence for individual distinctiveness. Primates 39:505-518. DOI: 10.1007/BF02557572. 
500

501

502

503

504

505

506

507

508

509

510

511

512

513

514

515

516

517

518

519

520

521

Baayen RH. 2008. Analyzing Linguistic Data: A Practical Introduction to Statistics using R. Cambridge University Press.

Barelli C., Mundry R., Heistermann M., Hammerschmidt K. 2013. Cues to androgens and quality in male gibbon songs. PLOS ONE 8:e82748. DOI:

10.1371/journal.pone.0082748.

Barr DJ., Levy R., Scheepers C., Tily HJ. 2013. Random effects structure for confirmatory hypothesis testing: Keep it maximal. Journal of Memory and Language 68:255-278. DOI: $10.1016 / j . j m l .2012 .11 .001$.

Bates D., Mächler M., Bolker B., Walker S. 2015. Fitting linear mixed-effects models using lme4. Journal of Statistical Software 67. DOI: 10.18637/jss.v067.i01.

Bates D., Maechler M., Bolker B., Walker S., Christensen RHB., Singmann H., Dai B., Grothendieck G., Green P. 2016. Ime4: Linear mixed-effects models using "Eigen" and S4.

Benítez ME., Roux A le., Fischer J., Beehner JC., Bergman TJ. 2016. Acoustic and temporal variation in gelada (Theropithecus gelada) loud calls advertise male quality. International Journal of Primatology 37:568-585. DOI: 10.1007/s10764-016-9922-0.

Boersma P. 2001. Praat, a system for doing phonetics by computer. Glot International 5:341345.

Boesch C. 1995. Innovation in wild chimpanzees (Pan troglodytes). International Journal of Primatology 16:1-16. DOI: 10.1007/BF02700150.

Boesch C. 2012. Wild Cultures: A Comparison between Chimpanzee and Human Cultures. Cambridge: Cambridge University Press. 
522 Boesch C., Boesch-Achermann H. 2000. The Chimpanzees of the Taï Forest: Behavioural 523 Ecology and Evolution. Oxford University Press.

524 Bowerman BL., O’Connell R. 2000. Linear Statistical Models: An Applied Approach. Belmont, $525 \quad$ Ca: Duxbury Press.

526 Briefer EF. 2012. Vocal expression of emotions in mammals: mechanisms of production and 527 evidence. Journal of Zoology 288:1-20. DOI: 10.1111/j.1469-7998.2012.00920.x.

528 Clark AP. 1993. Rank differences in the production of vocalizations by wild chimpanzees as a function of social context. American Journal of Primatology 31:159-179. DOI:

530 10.1002/ajp.1350310302.

531

532

Clutton-Brock T. 2016. Reproductive competition among males. In: Mammal Societies.

Chichester, UK: John Wiley \& Sons, 427-466.

533 Crockford C., Herbinger I., Vigilant L., Boesch C. 2004. Wild chimpanzees produce group534 specific calls: a case for vocal learning? Ethology 110:221-243. DOI: 10.1111/j.14390310.2004.00968.x.

536

537

538

539

540

541

542

Davies NB., Halliday TR. 1978. Deep croaks and fighting assessment in toads Bufo bufo. Nature 274:683-685. DOI: 10.1038/274683a0.

Delgado RA. 2006. Sexual selection in the loud calls of male primates: Signal content and function. International Journal of Primatology 27:5-25. DOI: 10.1007/s10764-005-90014.

Dobson AJ., Barnett A. 2008. An Introduction to Generalized Linear Models, Third Edition. Boca Raton: Chapman and Hall/CRC. 
543 East ML., Hofer H. 1991. Loud calling in a female-dominated mammalian society: II.

544 Behavioural contexts and functions of whooping of spotted hyaenas, Crocuta crocuta. Animal Behaviour 42:651-669. DOI: 10.1016/S0003-3472(05)80247-7.

546 Ey E., Pfefferle D., Fischer J. 2007. Do age- and sex-related variations reliably reflect body size in non-human primate vocalizations? A review. Primates 48:253-267. DOI: 10.1007/s10329-006-0033-y.

Fedurek P., Donnellan E., Slocombe KE. 2014. Social and ecological correlates of long-distance pant hoot calls in male chimpanzees. Behavioral Ecology and Sociobiology 68:13451355.

Fedurek P., Slocombe KE., Enigk DK., Thompson ME., Wrangham RW., Muller MN. 2016. The relationship between testosterone and long-distance calling in wild male chimpanzees. Behavioral Ecology and Sociobiology 70:659-672. DOI: 10.1007/s00265-016-2087-1.

Fedurek P., Zuberbühler K., Dahl CD. 2016. Sequential information in a great ape utterance. Scientific Reports 6:38226. DOI: 10.1038/srep38226.

557 Fischer J., Kitchen DM., Seyfarth RM., Cheney DL. 2004. Baboon loud calls advertise male quality: Acoustic features and their relation to rank, age, and exhaustion. Behavioral Ecology and Sociobiology 56:140-148. DOI: 10.1007/s00265-003-0739-4.

Fitch WT. 1997. Vocal tract length and formant frequency dispersion correlate with body size in rhesus macaques. The Journal of the Acoustical Society of America 102:1213-1222. DOI: 10.1121/1.421048.

Fitch WT., Hauser MD. 2003. Unpacking "honesty": Vertebrate vocal production and the evolution of acoustic signals. In: Simmons AM, Fay RR, Popper AN eds. Acoustic Communication. Springer Handbook of Auditory Research. Springer New York, 65-137. 
566 Forstmeier W., Schielzeth H. 2011. Cryptic multiple hypotheses testing in linear models:

567

568

569

570

571

572

573

574

575

576

577

578

579

580

581

582

583

584

585

586

587

588 overestimated effect sizes and the winner's curse. Behavioral Ecology and Sociobiology 65:47-55. DOI: 10.1007/s00265-010-1038-5.

Fox J., Weisberg HS. 2011. An R Companion to Applied Regression. Thousand Oaks, Calif: Sage Pubn.

Georgiev A. 2012. Energetic costs of reproductive effort in male chimpanzees. Doctoral dissertation Thesis. Cambridge, Mass: Harvard University.

Gil D., Gahr M. 2002. The honesty of bird song: multiple constraints for multiple traits. Trends in Ecology \& Evolution 17:133-141. DOI: 10.1016/S0169-5347(02)02410-2.

Haccou P., Meelis E. 1994. Statistical Analysis of Behavioural Data: An Approach Based on Time-structured Models. Oxford University Press.

Higham JP., Hebets EA. 2013. An introduction to multimodal communication. Behavioral Ecology and Sociobiology 67:1381-1388. DOI: 10.1007/s00265-013-1590-x.

Hobaiter C., Byrne RW. 2014. The meanings of chimpanzee gestures. Current Biology 24:15961600. DOI: $10.1016 /$ j.cub.2014.05.066.

Hobaiter C., Byrne RW., Zuberbühler K. 2017. Wild chimpanzees' use of single and combined vocal and gestural signals. Behavioral Ecology and Sociobiology 71:96. DOI: $10.1007 / \mathrm{s} 00265-017-2325-1$.

Kitchen DM., Seyfarth RM., Fischer J., Cheney DL. 2003. Loud calls as indicators of dominance in male baboons (Papio cynocephalus ursinus). Behavioral Ecology and Sociobiology 53:374-384. DOI: 10.1007/s00265-003-0588-1.

Kojima S., Izumi A., Ceugniet M. 2003. Identification of vocalizers by pant hoots, pant grunts and screams in a chimpanzee. Primates 44:225-230. DOI: $10.1007 / \mathrm{s} 10329-002-0014-8$. 
589 Leavens DA., Russell JL., Hopkins WD. 2010. Multimodal communication by captive 590 chimpanzees (Pan troglodytes). Animal Cognition 13:33-40. DOI: 10.1007/s10071-009-

591 0242-z.

592 Leeuwen EJC van., Cronin KA., Haun DBM., Mundry R., Bodamer MD. 2012. Neighbouring 593 chimpanzee communities show different preferences in social grooming behaviour. Proceedings of the Royal Society of London B: Biological Sciences. DOI: 10.1098/rspb.2012.1543.

Liebal K., Waller, BM., Slocombe, KE., Burrows, AM. 2013. Primate Communication: A Multimodal Approach. New York: Cambridge University Press.

Maestripieri D., Schino G., Aureli F., Troisi A. 1992. A modest proposal: Displacement activities as an indicator of emotions in primates. Animal Behaviour 44:967-979. DOI: Edition. Chapman and Hall/CRC. Zeitschrift für Tierpsychologie 38:97-109. DOI: 10.1111/j.1439-0310.1975.tb01994.x. $10.1016 / \mathrm{S} 0003-3472(05) 80592-5$.

Manly BFJ. 1997. Randomization, Bootstrap and Monte Carlo Methods in Biology, Second

\section{or Edition. Chapman and Hall/CRC.}

Marler P., Hobbett L. 1975. Individuality in a long-range vocalization of wild chimpanzees.

McClelland BE., Wilczynski W., Ryan MJ. 1996. Correlations between call characteristics and morphology in male cricket frogs (Acris crepitans). Journal of Experimental Biology 199:1907-1919.

McCullagh P., Nelder JA. 1989. Generalized Linear Models, Second Edition. Boca Raton: Chapman and Hall/CRC.

Mitani JC. 1985. Sexual selection and adult male orangutan long calls. Animal Behaviour 33:272-283. DOI: 10.1016/S0003-3472(85)80141-X. 
612 Mitani JC., Brandt KL. 1994. Social factors influence the acoustic variability in the long-distance

613 calls of male chimpanzees. Ethology 96:233-252. DOI: 10.1111/j.1439-

614 0310.1994.tb01012.x.

615 Mitani JC., Hunley KL., Murdoch ME. 1999. Geographic variation in the calls of wild

616 chimpanzees: a reassessment. American Journal of Primatology 47:133-151. DOI:

617 10.1002/(SICI)1098-2345(1999)47\%3A2<133\%3A\%3AAID-AJP4>3.0.CO\%3B2-I

618

619

620

621

622

623

624

625

626

627

628

629

630

631

632

633

634

Mitani JC., Nishida T. 1993. Contexts and social correlates of long-distance calling by male chimpanzees. Animal Behaviour 45:735-746. DOI: 10.1006/anbe.1993.1088.

Morton ES. 1977. On the occurrence and significance of motivation-structural rules in some bird and mammal sounds. The American Naturalist 111:855-869.

Muller MN., Mitani JC. 2005. Conflict and cooperation in wild chimpanzees. Advances in the Study of Behaviour 35:275-331.

Neumann C., Assahad G., Hammerschmidt K., Perwitasari-Farajallah D., Engelhardt A. 2010. Loud calls in male crested macaques, Macaca nigra: a signal of dominance in a tolerant species. Animal Behaviour 79:187-193. DOI: 10.1016/j.anbehav.2009.10.026.

Nishida T. 1980. The leaf-clipping display: A newly-discovered expressive gesture in wild chimpanzees. Journal of Human Evolution 9:117-128. DOI: 10.1016/00472484(80)90068-8.

Nolan PM., Hill GE. 2004. Female choice for song characteristics in the house finch. Animal Behaviour 67:403-410. DOI: 10.1016/j.anbehav.2003.03.018.

Notman H., Rendall D. 2005. Contextual variation in chimpanzee pant hoots and its implications for referential communication. Animal Behaviour 70:177-190. DOI: 10.1016/j.anbehav.2004.08.024. 
635 Pitcher BJ., Briefer EF., Vannoni E., McElligott AG. 2014. Fallow bucks attend to vocal cues of 636 motivation and fatigue. Behavioral Ecology 25:392-401. DOI: 10.1093/beheco/art131.

637 Potter DM., Griffiths DJ. 2006. Omnibus permutation tests of the overall null hypothesis in 638 datasets with many covariates. Journal of Biopharmaceutical Statistics 16:327-341. DOI:

639 $10.1080 / 10543400600609585$.

640

641

642

643

644

645

646

647

648

649

650

651

652

653

654

655 K., Cárdenas R., Burriss RP., Jablonski NG., Shriver MD., Weiss D., Lameira AR., Apicella CL., Owren MJ., Barelli C., Glenn ME., Ramos-Fernandez G. 2016. Sexual selection on male vocal fundamental frequency in humans and other anthropoids. Proceedings. Biological Sciences 283. DOI: 10.1098/rspb.2015.2830.

R Core Team. 2017. R: A language and environment for statistical computing. Vienna, Austria: R Foundation for Statistical Computing.

Reby D., McComb K. 2003. Anatomical constraints generate honesty: acoustic cues to age and weight in the roars of red deer stags. Animal Behaviour 65:519-530. DOI: 10.1006/anbe.2003.2078.

Reby D., McComb K., Cargnelutti B., Darwin C., Fitch WT., Clutton-Brock T. 2005. Red deer stags use formants as assessment cues during intrasexual agonistic interactions. Proceedings of the Royal Society B: Biological Sciences 272:941-947. DOI: 10.1098/rspb.2004.2954.

Ryan MJ., Kime NM. 2003. Selection on Long-Distance Acoustic Signals. In: Acoustic Communication. Springer Handbook of Auditory Research. Springer, New York, NY, 
656 Sanvito S., Galimberti F., Miller EH. 2007. Vocal signalling of male southern elephant seals is 657 honest but imprecise. Animal Behaviour 73:287-299. DOI:

$658 \quad$ 10.1016/j.anbehav.2006.08.005.

659 Schielzeth H., Forstmeier W. 2009. Conclusions beyond support: overconfident estimates in 660 mixed models. Behavioral Ecology 20:416-420.

661 Searcy WA., Andersson M. 1986. Sexual selection and the evolution of song. Annual Review of $662 \quad$ Ecology and Systematics 17:507-533.

663 Sugiyama Y. 1981. Observations on the population dynamics and behavior of wild chimpanzees 664 at Bossou, Guinea, in 1979-1980. Primates 22:435-444. DOI: 10.1007/BF02381236.

665 Vannoni E., McElligott AG. 2008. Low frequency groans indicate larger and more dominant 666 fallow deer (Dama dama) males. PLOS ONE 3:e3113. DOI:

667 10.1371/journal.pone.0003113.

668 Watts DP. 2007. Tool use by chimpanzees at Ngogo, Kibale National Park, Uganda. 669 International Journal of Primatology 29:83-94. DOI: 10.1007/s10764-007-9227-4.

Welch AM., Semlitsch RD., Gerhardt HC. 1998. Call duration as an indicator of genetic quality in male gray tree frogs. Science 280:1928-1930.

672 Whiten A., Goodall J., C W., Nishida T., Reynolds V., Sugiyama Y., G CE., W R., Boesch C. 1999. Cultures in chimpanzees. Nature 399:682-685. DOI: $10.1038 / 21415$.

674 Wich SA., Post DJ van der., Heistermann M., Möhle U., Hooff JARAM van., Sterck EHM. 2003. Life-phase related changes in male loud call characteristics and testosterone levels in wild thomas langurs. International Journal of Primatology 24:1251-1265. DOI:

677 10.1023/B:IJOP.0000005991.97232.2a. 
678 Wilke C., Kavanagh E., Donnellan E., Waller BM., Machanda ZP., Slocombe KE. 2017.

679 Production of and responses to unimodal and multimodal signals in wild chimpanzees, 680 Pan troglodytes schweinfurthii. Animal Behaviour 123:305-316. DOI:

$681 \quad$ 10.1016/j.anbehav.2016.10.024.

682 Wilson ML., Wrangham RW. 2003. Intergroup relations in chimpanzees. Annual Review of $683 \quad$ Anthropology 32:363-392.

684 


\section{Table $\mathbf{1}$ (on next page)}

Summary of the focal follow data for each male chimpanzee.

The total number of focal observation hours per individual before, during and after the alpha takeover and the total number of pant hoots and aggressive interactions (focal could be aggressor or victim) observed during these focal follows. 
1

\begin{tabular}{l|c|c|c|c|c} 
& \multicolumn{3}{|c|}{$\begin{array}{c}\text { Hours of observation } \\
\text { from focal follows }\end{array}$} & $\begin{array}{c}\text { \# of pant } \\
\text { hoots emitted }\end{array}$ & $\begin{array}{c}\text { \# of aggressive } \\
\text { interactions }\end{array}$ \\
\cline { 2 - 4 } & before & during & after & & 21 \\
\hline Jacobo & NA & 11.5 & 45 & 75 & 56 \\
\hline Kuba & 89.5 & 27.5 & 96.5 & 235 & 8 \\
\hline Romario & NA & NA & 74 & 121 & 34 \\
\hline Utan & 48.5 & 11.5 & 23.5 & 64 & 38
\end{tabular}

2

3 


\section{Table 2 (on next page)}

Names and rank(s) held during the eleven month study period for each male chimpanzee.

The number of high-quality pant hoot recordings collected before, during and after the alpha takeover that were used for acoustic analyses. Of these, the number of pant hoot recordings immediately preceded by a leaf clip per individual. 
1

\begin{tabular}{l|c|c|c|c|c|c|c} 
& \multirow{2}{*}{ Rank(s)* } & \multicolumn{4}{|c|}{$\begin{array}{c}\text { \# of pant hoots } \\
\text { recorded for analyses }\end{array}$} & \multicolumn{3}{c}{$\begin{array}{l}\text { \# of recorded pant } \\
\text { hoots preceded by } \\
\text { leaf clipping }\end{array}$} \\
\cline { 3 - 8 } & & before & during & after & before & during & after \\
\hline Jacobo & 4,3 & 0 & 3 & 19 & 0 & 0 & 0 \\
\hline Kuba & 2,1 & 9 & 37 & 46 & 0 & 8 & 6 \\
\hline Romario & 5,4 & 0 & 2 & 46 & 0 & 0 & 9 \\
\hline Utan & 3 & 10 & 9 & 2 & 0 & 0 & 0 \\
\hline Woodstock & 1,2 & 10 & 9 & 10 & 0 & 1 & 3 \\
\hline *ranks males held throughout the study period, $1=$ alpha
\end{tabular}

3

4 


\section{Table 3(on next page)}

Summary of the 18 GLMMs testing for various acoustic parameters of pant hoots produced by five chimpanzee males.

Test predictors included period of instability, caller rank, and whether leaf clipping preceded the pant hoot. Sample size refers to the total number of pant hoots per GLMM. 


\begin{tabular}{|c|c|c|c|c|c|}
\hline & Response Variable & $\begin{array}{c}\text { Transformation } \\
\text { of Response }\end{array}$ & $\begin{array}{l}\text { Error Structure } \\
\text { (Link Function) }\end{array}$ & $\begin{array}{l}\text { Sample } \\
\text { Size }\end{array}$ & $\begin{array}{l}\text { Full vs Null } \\
\text { Model } \\
\text { Comparison }\end{array}$ \\
\hline & total duration (s) & sqrt & $\begin{array}{c}\text { Gaussian } \\
\text { (identity) }\end{array}$ & 212 & $\begin{array}{c}\chi^{2}=15.03, \mathrm{df}=4, \\
P=0.0046\end{array}$ \\
\hline \multirow{5}{*}{ 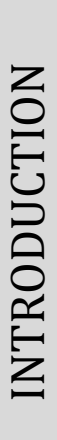 } & \# calls in the introduction & none & Poisson (log) & 173 & $\begin{array}{c}\chi^{2}=12.56, \mathrm{df}=4, \\
P=0.014\end{array}$ \\
\hline & introduction duration (s) & sqrt & $\begin{array}{l}\text { Gaussian } \\
\text { (identity) }\end{array}$ & 173 & $\begin{array}{c}\chi^{2}=12.52, \mathrm{df}=4, \\
P=0.014\end{array}$ \\
\hline & F0 of last call of the introduction $(\mathrm{Hz})$ & sqrt & $\begin{array}{c}\text { Gaussian } \\
\text { (identity) }\end{array}$ & 173 & $\begin{array}{c}\chi^{2}=5.67, \mathrm{df}=4 \\
P=0.23\end{array}$ \\
\hline & $\begin{array}{l}\text { duration of the last call of the } \\
\text { introduction (s) }\end{array}$ & none & $\begin{array}{r}\text { Gaussian } \\
\text { (identity) }\end{array}$ & 173 & $\begin{array}{c}\chi^{2}=5.35, \mathrm{df}=4, \\
P=0.25\end{array}$ \\
\hline & $\mathrm{pF}$ of the last call of the introduction $(\mathrm{Hz})$ & $\log$ & $\begin{array}{l}\text { Gaussian } \\
\text { (identity) }\end{array}$ & 173 & $\begin{array}{c}\chi^{2}=6.10, d f=4, \\
P=0.19\end{array}$ \\
\hline \multirow{5}{*}{ 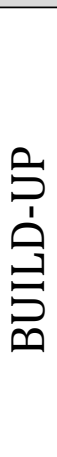 } & \# of voiced calls in the build-up & none & $\begin{array}{c}\text { Negative } \\
\text { Binomial }(\log ) \\
\end{array}$ & 189 & $\begin{array}{c}\chi^{2}=12.16, \mathrm{df}=4, \\
P=0.016\end{array}$ \\
\hline & duration of the build-up (s) & sqrt & $\begin{array}{r}\text { Gaussian } \\
\text { (identity) } \\
\end{array}$ & 189 & $\begin{array}{c}\chi^{2}=0.00, \mathrm{df}=4 \\
P=1.00\end{array}$ \\
\hline & $\begin{array}{l}\text { F0 of the middle call of the } \\
\text { build-up (Hz) }\end{array}$ & sqrt & $\begin{array}{r}\text { Gaussian } \\
\text { (identity) }\end{array}$ & 189 & $\begin{array}{c}\chi^{2}=18.10, \mathrm{df}=4, \\
P=0.0012\end{array}$ \\
\hline & duration of the middle call of the build-up & $\log (x 1000)$ & $\begin{array}{r}\text { Gaussian } \\
\text { (identity) }\end{array}$ & 189 & $\begin{array}{c}\chi^{2}=13.87, \mathrm{df}=4, \\
P=0.0077\end{array}$ \\
\hline & $\mathrm{pF}$ of the middle call of the build-up (Hz) & $\log$ & $\begin{array}{l}\text { Gaussian } \\
\text { (identity) }\end{array}$ & 189 & $\begin{array}{c}\chi^{2}=16.11, \mathrm{df}=4, \\
P=0.0029\end{array}$ \\
\hline \multirow{7}{*}{ 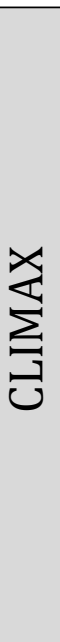 } & \# of elements in the climax & none & $\begin{array}{c}\text { Negative } \\
\text { Binomial (log) }\end{array}$ & 189 & $\begin{array}{c}\chi^{2}=28.59, \mathrm{df}=4, \\
P=0.00001\end{array}$ \\
\hline & duration of the climax (s) & sqrt & $\begin{array}{c}\text { Gaussian } \\
\text { (identity) }\end{array}$ & 189 & $\begin{array}{c}\chi^{2}=21.61, \mathrm{df}=4, \\
\mathrm{P}=0.00024\end{array}$ \\
\hline & F0 of the highest call of the climax $(\mathrm{Hz})$ & none & $\begin{array}{r}\text { Gaussian } \\
\text { (identity) }\end{array}$ & 127 & $\begin{array}{c}\chi^{2}=7.27, \mathrm{df}=4 \\
P=0.12\end{array}$ \\
\hline & $\begin{array}{l}\text { duration of the highest call of the } \\
\text { climax }(\mathrm{s})\end{array}$ & none & $\begin{array}{r}\text { Gaussian } \\
\text { (identity) }\end{array}$ & 127 & $\begin{array}{l}\chi^{2}=2.46, \mathrm{df}=4 \\
P=0.65\end{array}$ \\
\hline & $\mathrm{pF}$ of the highest call of the climax $(\mathrm{Hz})$ & $\log$ & $\begin{array}{l}\text { Gaussian } \\
\text { (identity) }\end{array}$ & 127 & $\begin{array}{c}\chi^{2}=11.28, \mathrm{df}=4, \\
P=0.024\end{array}$ \\
\hline & duration of drumming (s)* & sqrt & $\begin{array}{l}\text { Gaussian } \\
\text { (identity) }\end{array}$ & 210 & $\begin{array}{c}\chi^{2}=33.06, \mathrm{df}=4 \\
P<0.00001\end{array}$ \\
\hline & \# of drum beats* & none & $\begin{array}{c}\text { Negative } \\
\text { Binomial }(\log )\end{array}$ & 210 & $\begin{array}{c}\chi^{2}=24.01, \mathrm{df}=4 \\
P=0.00008\end{array}$ \\
\hline
\end{tabular}


Table 4(on next page)

Summary of the direction of significant effects $(P<0.05)$ of the three predictors on the twelve acoustic pant hoot variables which revealed significant full versus null model comparisons. 


\begin{tabular}{|c|c|c|c|}
\hline & Period of Instability & Leaf Clipping & Rank \\
\hline total duration & & & - \\
\hline $\begin{array}{l}\text { \# of calls in } \\
\text { introduction phase }\end{array}$ & - & - & \\
\hline $\begin{array}{l}\text { duration of } \\
\text { introduction phase }\end{array}$ & & & \\
\hline $\begin{array}{l}\# \text { of voiced calls in } \\
\text { build-up phase }\end{array}$ & & & \\
\hline $\begin{array}{l}\text { F0 of the middle call } \\
\text { of build-up phase }\end{array}$ & & & - \\
\hline $\begin{array}{l}\text { duration of the middle } \\
\text { call of the build-up }\end{array}$ & & & - \\
\hline $\begin{array}{l}\text { pF of the middle call } \\
\text { of build-up phase }\end{array}$ & & & - \\
\hline $\begin{array}{l}\text { \# of elements in } \\
\text { climax phase }\end{array}$ & & & - \\
\hline $\begin{array}{l}\text { duration of climax } \\
\text { phase }\end{array}$ & & & - \\
\hline $\begin{array}{l}\text { the maximum } \mathrm{pF} \text { of a } \\
\text { climax call }\end{array}$ & & - & - \\
\hline $\begin{array}{l}\text { duration of total } \\
\text { drumming }\end{array}$ & & & - \\
\hline \# of drum beats & & & - \\
\hline
\end{tabular}

2 (Period of Instability: during and/or after the alpha takeover occurred relative to before; Leaf clipping: when

3 leaf clipping preceded the pant hoot; Rank: as rank increases in dominance; unfilled arrows $\mathrm{P}<0.1$ ). 


\section{Figure 1}

A spectrogram of a male chimpanzee pant hoot vocalization preceded by leaf clipping.

Curved lines identify the three main phases: introduction, build-up and climax while boxes denote the call targeted for further analyses within each phase. Both leaf clipping and buttress drumming also occur in this pant hoot and are indicated with arrows.

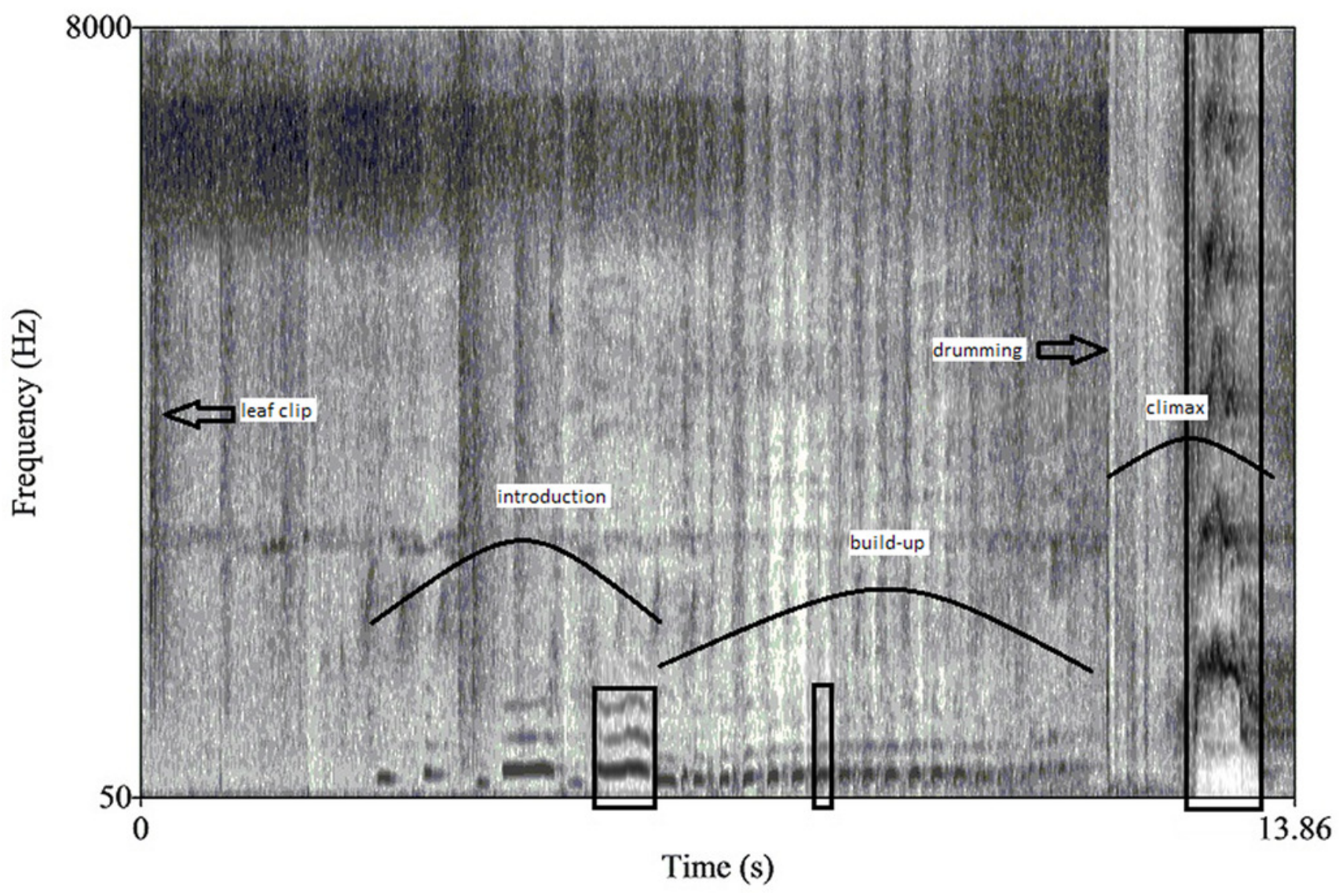




\section{Figure 2}

Variation in eight acoustic parameters of male chimpanzee pant hoots that were significantly affected by both leaf clipping and the period of instability.

Plots show the median (solid horizontal line) for each acoustic parameter. The boxes represent quartiles and the vertical lines show percentiles (2.5 and 97.5\%). The y-axis is the acoustic parameter and the $\mathrm{x}$-axis shows the levels of the two factors: leaf clipping and period of instability (before, during and after the alpha takeover). The dashed horizontal line shows the model prediction given all other fixed effects being at their average value. 

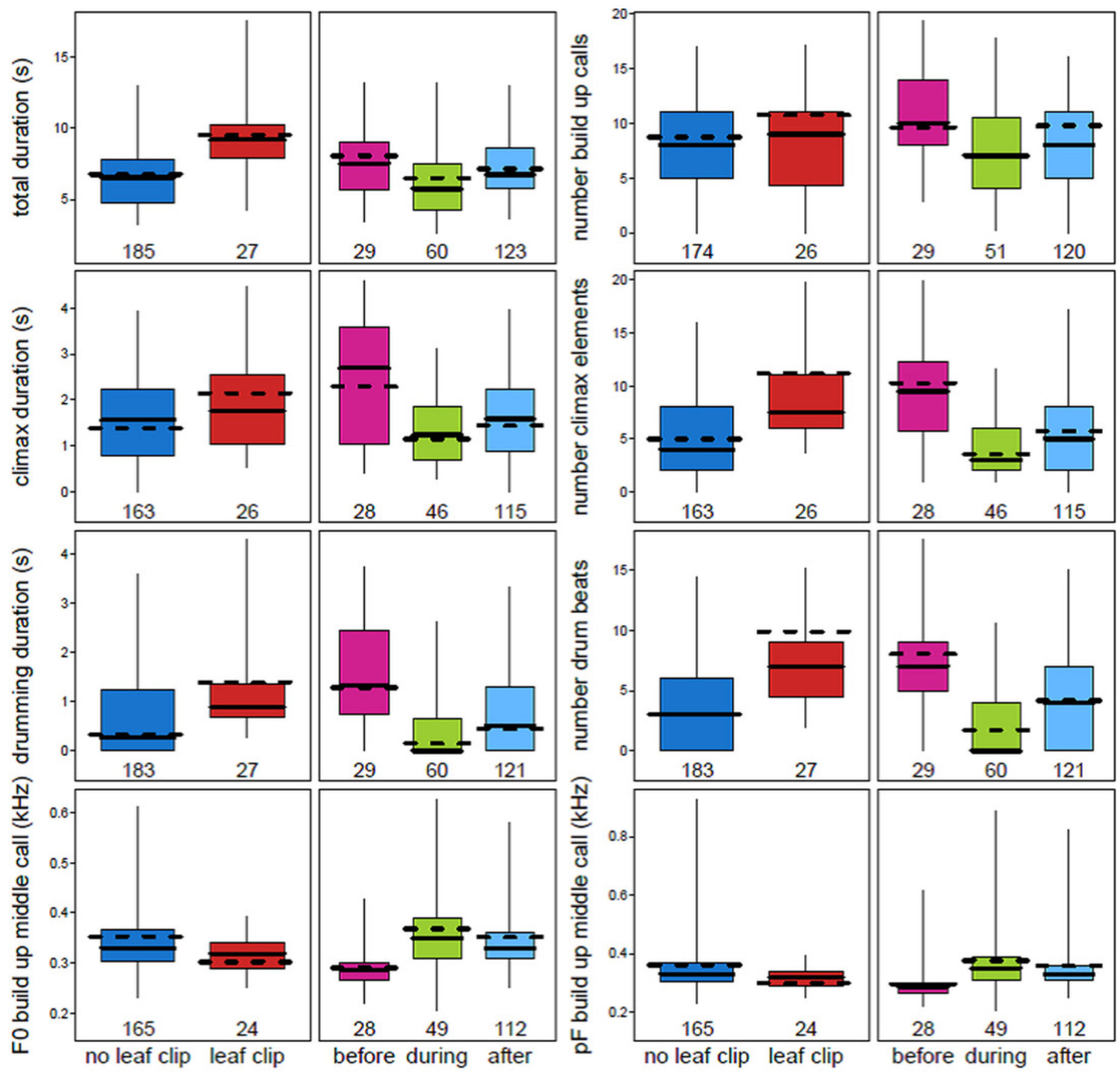
Figure 3

Median rates of pant hooting (a) and aggression (b) per hour for each focal chimpanzee male before, during and after the alpha takeover.

Lines connect points of the same respective individual where applicable.
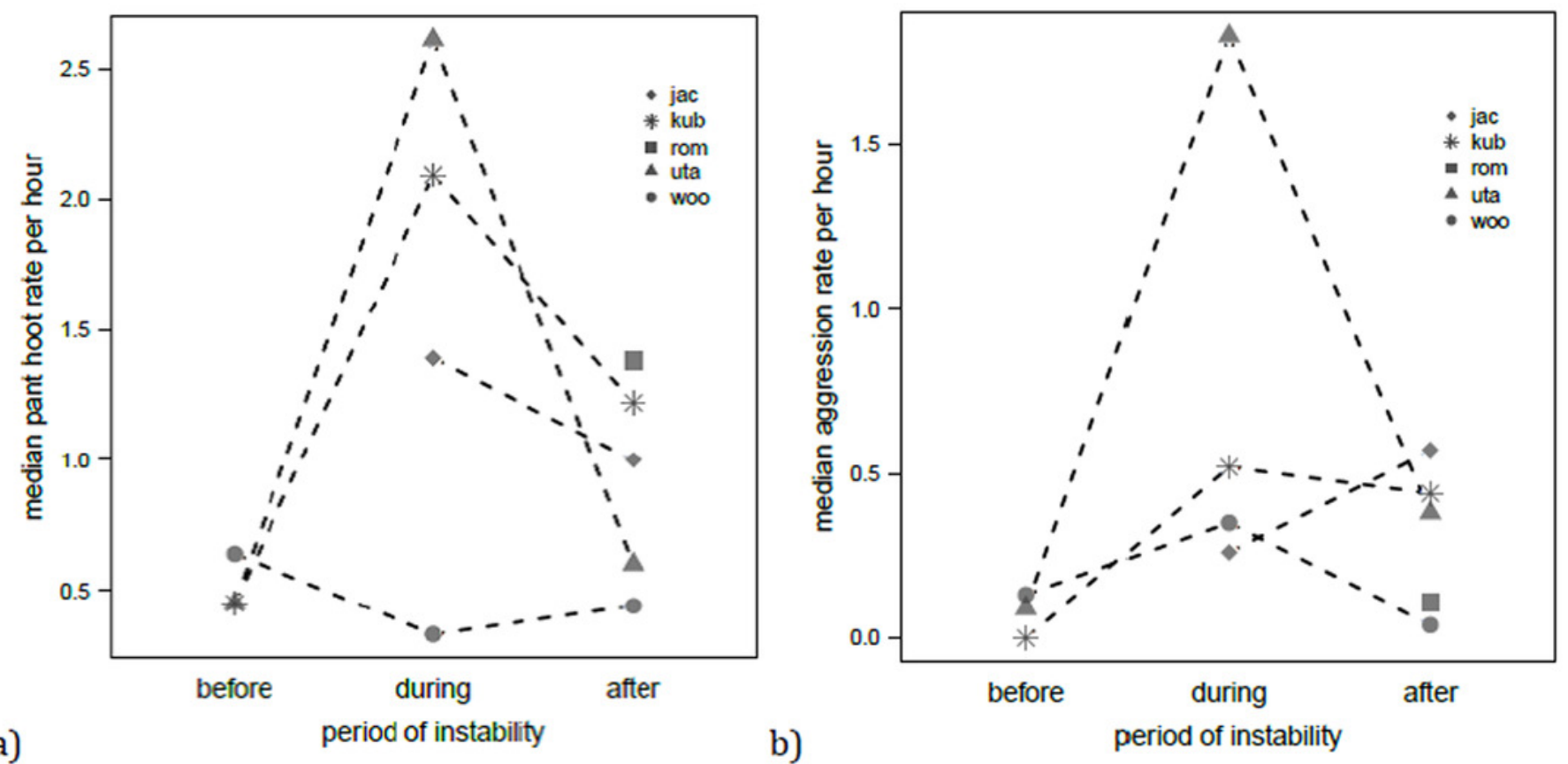